\title{
Trade, Technology, and Wages: General Equilibrium Mechanics
}

\author{
Joseph F. Francois \\ Erasmus University Rotterdamand CEPR \\ D oulas Nelson \\ TulaneUnivesityand CREDIT
}

April 1998

\begin{abstract}
This paper highlights analytical reasons why we believe trade and technology are linked to wage movements in general, and how we should organize our examination of the recent episode of wage and employment erosion in the OECD countries. We start with a graphic tour through the mechanics of general equilibrium theory on trade and wages. This provides a set of implied relationships between wages and factor intensity trends that, together, provide a casual test of the consistency of posited relationships with actual trends. Numeric analysis and a review of the general equilibrium empirical literature follow the theoretical overview.
\end{abstract}

This paper represents the views of the authors. It is not meant to represent the views of any institution with which they may have ever been affiliated. Thanks are due to workshop participants at the Royal Economic Society Meetings, and at the University of Nottingham, as well as to Matthew Slaughter and Adrian Wood. 


\section{Trade, Technology, and Wages: General Equilibrium Mechanics}

Markets areinterdependent. Like the equally valid claim that reality is a seamless whole, this observation can be a useful reminder of the difficulties we face as policy analysts. ${ }^{1}$ One way of avoiding the problems that arise with general equilibrium reasoning as a basis of policy analysis is to eschew general equilibrium altogether in favor of partial equilibrium analysis. This is an uneasy compromise in the best of circumstances (empirical convenience is no guarantee of analytical accuracy), but when the issue at hand is the link between international trade and relative wages, there is simply no substitute for general equilibrium analysis. Once embarked on a general equilibrium analysis, however, there is considerable art in the science. We must maintain an appropriate balance between the clarity and discipline imparted by the analytical framework and the compromises required if we are to extract compelling results.

O ur view is that, when we as economists confront the question of trade and wage linkages, the appropriate balance to achieve clarity is critical. It is true that there are labour market issues that require detailed analysis of the type favored in the labour economics field (a level of detail somewhat antithetical to general equilibrium analysis). However, meaningful exploration of the trade and wage nexus requires a clear understanding and treatment of the general equilibrium mechanisms at play. With this principle in mind, our goal in this paper is to highlight the analytical reasons why we believe trade and technology are linked to wage movements in general, and howwe should organize our examination of the episode of wage and employment erosion in the OECD countries. To accomplish this, we start with a graphic tour through the mechanics of the most basic general equilibrium theory on trade and wages. This provides a set of implied relationships between wages and factor intensity trends that, together, provide a casual test of the consistency of posited relationships with actual trends. This is followed by an examination of the strength of the various mechanisms (trade, innovation, etc.) highlighted by the theory, through numeric analysis. We then relate this theoretical overview to the empirical literature.

${ }^{1}$ Abstract general equilibrium theory contains many results that stress precisely the difficulties of deriving clear comparative static results in all but the most tightly constrained models. The flavour of these results can be tasted in the title of Sonnenschein's (1973) well known paper "D o Walras' Identity and Continuity Characterize the Class of Excess D emand Functions?" See also the surveys by Mantel (1977) and Shafer and Sonnenschein (1982). 


\section{TRADE AND WAGESIN THE 2x2 MODEL}

\section{TheBasicModd}

The parentage of our intuition on the general equilibrium relationship between trade and labour market conditions can be traced to the classic $2 \times 2$ model. It is here that the linkages are made most explicit. In this framework, the theory predicts rather directly, as Wood (1995) and others have emphasized, that if prices are driven down for unskilled labour-intensive goods (an assumed byproduct of trade with low-wage countries), there will be unskilled wage erosion in skill-intensive countries (i.e. the OECD countries). Of course, the very assumptions that make such a model tractable may also sterilize potentially critical links in the causal chain of events (a point we return to later in this section). O ur goal in retracing these mechanisms here is to highlight some implications of the theory that are central to the trade-wage linkage. In essence, we are setting them up for a later confrontation with casual empirical evidence.

Any study of international trade requires at least two goods (an importable and an exportable) and any study of income distribution requires some form of household heterogeneity. This is the basis of the claim that a proper examination of the problem requires a general equilibrium approach. ${ }^{2}$ While there are a wide variety of ways to generate household heterogeneity, the easiest way is to permit endowment heterogeneity. ${ }^{3}$ The canonical model of this sort is the 2good x 2-factor, Heckscher-O hlin-Samuelson (HOS) model. The HO S standard assumptions are:

1. Behavioural/ Institutional assumptions

- Rational behaviour by households and firms

- Complete, perfectly competitive markets

${ }^{2}$ It certainly is coherent to discuss trade policy in partial equilibrium, with household heterogeneity based on either a producer/ consumer dichotomy or, as in contemporary work on trade and wages by labour economists or strategic trade theory, a more detailed characterization of competitive conditions within the industry. However, contrary to its prominence in text book discussions of the political economy of trade policy, the producer/ consumer dichotomy seems to have very little to do with the way citizens or policy-makers actually think about trade policy. Similarly, it has proven rather difficult to find sectors corresponding to the conditions yielding successful strategic trade theory (the sole exception being the aerospace industry). The labour economists' approach, while informative, would appear to require incorporation within a general equilibrium framework to provide a fully compelling account. We do not pursue these issues here, but see G aston and Nelson (1997) for a detailed discussion of the substantial gains achieved in recent work by labour econonmists on the trade-wage linkages.

${ }^{3}$ O ther obvious candidates are taste heterogeneity and portfolio heterogeneity. 
- Two countries

- Balanced trade

2. Both countries possess idantical tastes that can be represented by identical systems of (homothetic) community indifference curves.

3. Each country is endowed with fixed quantities of tho factars of production (which we denote unskilled labour (L) and skilled labour/ human capital $(\mathrm{H})$ ). These factors earn incomes wand r respectively.

- Factors are assumed to be of uniformquality.

- Factors are assumed to be pefectlymobilebetween setars

- Factors are assumed to be pefeetlyimmdilebetwen cuntries

4. There are twogoods

- Both countries share the same technological opportunities.

- Each good requires strictly positive inputs of both $\mathrm{H}$ and $\mathrm{L}$ to be produced in positive quantities

- These production functions are linear homogeneous, twice differentiable, and strictly concave.

5. Fador-intensity. At all relevant factor prices, it will be assumed that one of the goods is always human capital intensive relative to the other. Let $\mathrm{a}_{\mathrm{j}}$ be the input of factor $\mathrm{i}$ needed to produce one unit of good $\mathrm{j}^{4}{ }^{4}$ We then have:

$$
\frac{a_{H Y}}{a_{L Y}}>\frac{a_{H X}}{a_{L X}}
$$

6. factorabundance $\mathrm{O}$ ne of the countries is taken to be relatively more richly endowed with human capital than the other. Letting a "-" denote a fixed endowment and a "*"

${ }^{4}$ Throughout this paper the set of factors is denoted $\mathrm{M}$, a characteristic element is i; the set of commodities is denoted $\mathrm{N}$, a characteristic element is denoted $\mathrm{j}$. Where there are more than two elements in these sets, $\mathrm{i}$ can range from 1 to mand $\mathrm{j}$ can range from 1 to $\mathrm{n}$ 
denote the Foreign country, this is:

$$
\frac{\bar{H}}{\bar{L}}>\frac{\bar{H} *}{\bar{L} *}
$$

7. International trade in goods is costless.

These are strong assumptions, but with them we have created a minimally complex general equilibrium model with both inter-sectoral and intra-sectoral (i.e. inter-factoral) effects. Furthermore, we have isolated the relationship between factor-intensity and factor-endowment as the basis of trade. Because most of us take this to be empirically central, we have a certain confidence in the predictions of this model as a starting point for our intuition about the causes and effects of international trade.

Under the assumptions listed above, we have the following well known result:

Stdper-Samulson Therem An increase in the relative price of one of the goods will raise the return to the factor used intensively in the production of that good, relative to all other prices, and lower the return to the other factor, relative to all other prices.

This property of the $2 \times 2$ model is often illustrated with the Lerner-Pearce diagram. We have done so in Fig.1. In the figure, we have projected the unit-value isoquants for each of the two goods into $\mathrm{H}-\mathrm{L}$ space. Since the unit isoquant gives all combinations of $\mathrm{H}$ and $\mathrm{L}$ that can produce one physical unit of output, and since that unit sells for a price $P_{j}$, then we divide by $P_{j}$ to scale the quantity back to $\$ 1$ worth of output at the given price. With price equal to cost under constant returns and competitive markets, each isoquant must be tangent to the $\$ 1$ isocost line. ${ }^{5}$ This is represented by points 1 and 3. Thus the equilibrium illustrated in Fig.1 reflects relative prices and relative factor incomes. Following (1), the figure reflects our assumption that production of good $\mathrm{Y}$ is human capital $(\mathrm{H})$ intensive relative to good $\mathrm{X}$.

\section{- figure 1 about here -}

${ }^{5}$ The isocost line gives all combinations of $\mathrm{H}$ and $\mathrm{L}$ that can be purchased for $\$ 1$ at relative factor prices given by the slope: $1=\mathrm{nH}+\mathrm{wL}$ or $\mathrm{H}=1 / \mathrm{r}-\mathrm{w} \mathrm{rL}$. Note that wis the payment per unit labor ("wage") and rthe payment per unit human capital ("rental"). 
Suppose we consider an archetypal OECD economy, taken to be relatively abundant in $\mathrm{H}$ (and thus an exporter of good $\mathrm{Y}$ ). Now consider a reduction in protection, and assume for now that the country is economically small. (Identically for this discussion, we could argue that the drop in internal price for $\mathrm{X}$ is due to changing supply conditions, such as economic expansion, in the South region exporting X.) Since the $\mathrm{L}$-intensive good $\mathrm{X}$ is importable, the result is a fall in the price of good X, represented by an outward shift in the unit value isoquant for good X. As illustrated, if good $\mathrm{X}$ is to be produced in the new equilibrium, the w r ratio must fall to permit a tangency at points 2 and 4 for both of the new unit-value isoquants. This is the fiendsandeneries part of the Stolper-Samuelson theorem: each factor has a good that is a friend and a good that is an enemy. ${ }^{6}$ In this case, good $\mathrm{Y}$ is a friend to $\mathrm{H}$ and an enemy to $\mathrm{L}$; $\operatorname{good} \mathrm{X}$ is a friend to $\mathrm{L}$ and an enemy to $\mathrm{H}$. The other part of the theorem asserts a magification effect: that the factor-price changes are magnified relative to the commodity-price changes. ${ }^{7}$ We can see the magnification effect by recognizing that the intercepts of the isocost line give $1 / \mathrm{r}$ and $1 / \mathrm{w}$ Thus, the fact that the new H-intercept is below the initial intercept implies that rhas risen and, since the price of good $\mathrm{Y}$ is unchanged and that of good $\mathrm{X}$ has fallen, this implies an increase in the real wage (i.e. a magnification). Similarly, since the new L-intercept is to the right of the old one implies that whas fallen. Furthermore, since the distance from point $1 /$ wto point 5 in the figure is proportional to the increase in price, and the wage has actually fallen by $1 / w^{\prime}-1 / w$ the reduction in the wage is a magnification of the fall in the price of good X. Using hats to denote proportional changes, we have:

$$
\hat{r}>\hat{p}_{Y}(=0)>\hat{P}_{X}>\hat{w}
$$

${ }^{6} \mathrm{~A}$ good is a friend to a factor if an increase in its price causes an increase in the factor's price, and an enemy if an increase in its price causes a decrease in the factor's price. This terminology is essentially that of Jones and Schienkman (1977). If a good is a magnified friend to a factor, we will follow Jones and Schienkman in referring to the factor as a natural friend to the good, and similarly for enemies.

${ }^{7}$ As Jones (1965) makes clear, this is a function of the fact, derived from zero profits and cost minimization, that the proportional change in a commodity price must be a distributive share weighted average of the proportional changes in factor prices. As a result, commodityprice changes must be bound between factor-price changes. So, given perfect factor mobility and the factor-intensity assumption, a change in relative commodity prices must result in one factor-price increasing by more than the largest price change and the other by less than the smallest commodity price change. 
It is useful to restate the key elements of this result for the HOS case: every good has a friend and an enemy; and these relations are magnified. This result is striking enough, but in the HO S case it is also true that these relations are (almost) global, in both the mathematical and the geographical senses. Mathematically, as long as the economy is unspecialized, the same good is always a friend to a given factor and an enemy to the other factor. That is, under the assumptions given above, good $\mathrm{Y}$ is a friend to human capital and an enemy to unskilled labour for all prices that permit non-specialized production. G eographically, since this is a purely technological relationship, and all countries share the same technology, countries that experience the same price shock experience qualitatively the same relative factor-price effects. Furthermore, since factor-intensity reversals are ruled out in assumption 5 above, the identity of a given factor's friend and enemy can be predicted based on relative factor-intensity of the two commodities. If we take the HOS model as a serious representation of a given economy, say the United States, each of these three results is a falsifiable empirical claim.

To this point we have been discussing what D eardorff (1994) calls the essential version of the Stolper-Samuelson theorem. That is, we have not mentioned trade in any essential way, only the relationship between the relative commodity-prices observed by producers and the relative factor-prices. However, much of the current empirical research on the labour market effects of trade reasons from increased vdumeof trade with developing countries to reduced unskilled wages via the, perfectly plausible, assumption that developing countries are unskilled labour abundant. That is, much as the original Stolper-Samuelson result sought to make a statement of the form: "a reduction in protection lowers the real wage of the scarce factor and raises that of the abundant factor"; current research on trade and wages wants to make a claim of the form: "increased intensity of trade with developing countries lowers the real wage of the scarce factor (i.e. unskilled labour) and raises that of the abundant factor (skilled labour)". This increased trade intensity (as reflected in increased trade volumes) could be accounted for by reduced protection in industrial countries, reduced transportation costs, policy reform or technological change in developing countries, or some combination of these various factors. Critical to a coherent formalization of such a mechanism is a direct linkage between trade volumes (as emphasized in the recent labour literature) and trade prices (which are what ultimately link trade flows with wages).

There are both theoretical and empirical difficulties with the line of reasoning sketched above. ${ }^{8}$ First, as Lloyd Metzler (1949) showed, even under the assumptions listed above, if the

${ }^{8}$ The theoretical difficulties related to the simple statement of the Stolper-Samuelson theorem as a link between protection and returns to the scarce factor are particularly well 
Foreign offer curve is inelastic at the initial equilibrium, an increase in the tariff may improve the terms-of-trade so much that Home market relative price of the protected good actually falls. Then, by the logic of the magnification result, the scarce factor is actually hurt by the tariff. If the assumptions of internationally identical homothetic preferences and no factor-intensity reversal in internationally identical, linear homogeneous technologies are dropped, the link between (readily observable) factor-endowments and comparative advantage are undermined. Perhaps more importantly, to exploit the Stolper-Samuelson theorem, the increased trade intensity must have its effect through a fall in the relative price of unskilled labour-intensive goods and, as Bhagwati (1991) and Lawrence and Slaughter (1993) suggest, this pattern of price changes is not apparent in the data.

There are other difficulties that stem from real world departures from the assumptions underlying the $2 \times 2$ model as spelled out above. Before taking up the empirical content of the Stolper-Samuelson theorem, it will prove useful to consider the implications of two directions of generalization that seem particularly appropriate: the introduction of intermediate goods; and increasing the dimensionality from $2 \times 2$.

\section{Intermediates}

As Jones and Schienkman (1977) emphasize, the HOS model is special in two ways: the dimensionality is low; and the number of factors is equal to the number of goods. D ue to the low dimensionality of the standard $2 \times 2$ model, the effects of changes in the international trade environment on income distribution are very direct. In particular, the Stolper-Samuelson theorem offers a strong theoretical link between policies that change commodity prices (like tariffs and other trade barriers) and household welfare (through the effect of factor-prices on household income). However, it should be quite clear that this tractability comes at some considerable cost--the assumed low dimensionality, and the lack of any intermediate sectoral linkages. Both features are clearly falsified by the most casual empiricism. Thus, it is important to ask how sensitive the results of the HOS model (especially the Stolper-Samuelson theorem that is so central to our analysis) are to alternative assumptions about dimensionality and inter-sectoral linkages. Because the StolperSamuelson theorem is so intuitively appealing, it is important to understand the ways that the theorem depends on the assumptions of the model. The questions is, to what extent are the results of the model dependent on these properties.

In the $2 \times 2$ model spelled out above, intermediate linkages between sectors are assumed

exposited in Bhagwati (1959). 
away. Yet, as Ethier (1982) has emphasized, the majority or real world flows involve intermediates. This is true at both the national accounts level, and at the international trade level. These linkages are also closely linked to two-way trade patterns. For precisely these reasons, two-way trade models have joined the more senior $2 \times 2$ model in the trade theory pantheon.

Even if we keep all of the other assumptions made above intact, the introduction of interindustry linkages drives a wedge into the causal chain connecting trade prices and real wages. In particular, while there will still exist a mechanism tying goods prices with factor prices this mechanism will be less direct than before. The mapping goes from goods prices to value added prices, and then from value added prices to relative factor prices. At the margin, it turns out that this actually magnifies the magnification effect of the basic model. The extent to which price changes at the final good level translate into value added price changes then depend on the technical coefficients and the relative intensity of intermediate linkages.

So far, we have claimed that introducing inter-industry linkages does not weaken (and actually strengthens) the basic magnification effect. However, this is because we have kept the assumption of homogeneous goods. The more recent literature on trade with inter-industry linkages emphasises product differentiation at stages of intermediate use. In this setting, even if we keep 2 final goods and 2 factors, the standard Stolper-Samuelson results may no longer hold. In particular, in a 2x2 framework expanded to include intermediate products that are specialized, the net effect of trade and trade liberalisation on equilibrium wages depends critically on global variety and scale effects related to specialisation of differentiated goods. ${ }^{9}$

\section{Themx ncase}

We turn next to the Stolper-Samuelson result in a world with more than 2 goods and factors. O ne approach to developing high dimensional generalizations of the main comparative statics for the Heckscher-O hlin-Samuelson model involves attempts to find sufficient conditions such that results like the Stolper-Samuelson and Rybczynski theorems hold. ${ }^{10}$ Such generalizations are possible only

${ }^{9}$ Francois (1996) makes precisely this point, which is also carried in the recent literature on geography and the location of industry (Puga and Venables 1997). O ther departures from the standard 2x2 paradigm, like labour market imperfections, further weaken our case for being able to make generalisations about trade and labour market linkages. See Shiells and Thierfelder (1997) on this point.

${ }^{10}$ See Ethier (1981) for a truly magisterial survey of the full range of issues associated with dimensional generalization. D eardorff and Stern (1994) contains not only the original statement of the Stolper-Samuelson theorem, but a number of the major generalizations. 
when the world is square (i.e. $m=n$, so that we have as many goods as factors). Even then, a square world is far from sufficient. While this literature has provided great insight into the mathematical structure of trade models, it seems fair to say that little in the way of intuitively appealing economic insight has been generated, while the assumptions on the structure necessary to develop any results at all are extremely strong. O ne important, though negative, result that has emerged from this literature is that, even for the $\mathrm{m}=\mathrm{n}$ case, the prospects for identifying gdbal friends and enemies are extremely slim. An alternative approach jettisons both magnification and explicit identification of gainers and losers to get results that identify friends and enemies onaverage These results represent a strong generalization of one underlying aspect of the Stolper-Samuelson theorem. However, from the perspective of helping with explaining the link, if any, between trade and wages, the results of this class of models are weak precisely where we need them to be strong in identifying the gainers and losers speifically.

Another class of results, developed in a series of papers by Jones and Schienkman (1977), Diewert and Woodland (1977) and Chang (1979) are derived from the full system of fullemployment and zero-profit conditions. These models use the properties of partitioned matrices to derive local magnified friend and enemy relations for the $\mathrm{mx} n$ case. In particular, the authors are able to show that every good is a natural enemy to some factor, but that a given good need not be a natural friend to any factor. Perhaps more important from the perspective of income distribution issues is the question of whether every factor has a natural friend and/ or a natural enemy. Unfortunately, such results do not appear to be available for the mx ncase. Even if we are willing to assume that $\mathrm{m}=\mathrm{n}$ it can be shown that every factor must have a natural enemy, but it cannot be shown that every factor has a natural friend.

\section{FACTOR INTENSITIES IN THE 2x2 MODEL}

In Section I we focused directly on wage and price linkages. There are, in addition, factor allocation effects that go hand and hand with wage effects. These can provide an important general equilibrium check on the direct evidence. As originally stressed by Stolper and Samuelson (1941, pp. 349-350), the mechanism that can produce falling wages through price changes also implies the striking, though initially counter-intuitive, fact that if the price of the labour-intensive good falls both industries become more labour intensive. ${ }^{11}$ This is easily seen by returning to Fig.1. Note that

${ }^{11}$ This result is more general, and follows from cost minimization. IF we observe lower $(\mathrm{w} / \mathrm{r}$ ) ratios from goods price changes, then cost minimization means that we will at the same time observe a higher L intensity. This must hold for $\mathrm{n}$ sectors. 
at the new equilibrium points 2 and 4, both sectors have become more L intensive. As Lawrence and Slaughter (1993), Krugman and Lawrence (1994), and Baldwin (1995) argue, the fact that factor intensities should change in conjunction with wage shifts is troubling for proponents of a simple Stolper-Samuelson account of increasing wage inequality. In fact, over the 1980s we have observed exactly the opposite trend. The trends they point to in this regard are illustrated in Fig. 2 with data from the U.S. Department of Labour. As the figure shows, in the United States, the unskilled/ direct labour content of output has declined in manufacturing, not risen, since 1980. If anything, the divergent sectoral trends point to a complex mix of factors driving wage and employment trends.

\section{- figure 2 about here -}

Krugman and Lawrence and Baldwin are correct in pointing to the inconsistency between observed wage and factor intensity trends and a postulated Stolper-Samuelson mechanism at work. However, certain strains of the standard alternate explanation suffer from the same drawback. Consider, for example, economywide technical change that enhances productivity for skilled labour. It is straightforward to show, in a setting like Fig. 1, that this type of factor-biased technical change also fails the factor intensity test.

A causal mechanism in the $2 \mathrm{x} 2$ model that does generate effects more or less consistent with observed data trends is technical change that is both factor- and sector-biased. This mechanism is illustrated in Fig. 3. In the figure, we have initial equilibria at points 1 and 2, with tangencies of the ( $\mathrm{W} \mathrm{r})$ ratio with the unit valued isoquants. We have represented biased technical change as a shift of the unit isoquant for good $\mathrm{Y}^{12}$ This implies unskilled-labour saving technical change in the skill-intensive sector. The new equilibrium is located at points 3 and 4 . In the new equilibrium, the $\mathrm{Y}$ sector employs less unskilled labour per unit of output, while the $\mathrm{X}$ sector becomes more unskill intensive to accommodate the otherwise surplus supply of L. What happens to wages? Recall that we can read factor income as the reciprocal of the intercept point of the ( $\mathrm{W} r$ ) line with the $\mathrm{H}$ and $\mathrm{L}$ axis. With unchanged goods prices, this is the measure of real factor income changes. Given the shift of the unit-value isoquant for $\mathrm{X}$, the new ( $\mathrm{W} \mathrm{r}$ ) line must be flatter than the old one to maintain tangency along both unit-value isoquants. This implies an outward shift of the intercept point along the $\mathrm{L}$ axis, and hence a fall in real wages for unskilled labour. At the

\footnotetext{
${ }^{12}$ Findlay and Grubert (1959) provide a detailed analysis of technical change using the Lerner-Pearce framework. Also see section IX of Jones (1965) for a clear algebraic treatment of technical change in the two-sector case.
} 
same time, note that the relative factor intensity lines move in opposite directions, so that $\mathrm{Y}$ becomes more $\mathrm{H}$ intensive even as the ( $\mathrm{W} r$ ) ratio falls. The final outcome is a mix of falling real wages and mixed factor intensity shifts, in a pattern broadly consistent with recent experience.

\section{- figure 3 about here -}

\section{THEORY WITH NUMBERS: NUMERIC EXAMPLES}

In section IV, we discuss recent econometric evidence. Before doing so, however, we turn in this section to numeric examples of the general equilibrium mechanics outlined above. These serve to illustrate the implications that various departures from the standard 2x2 carry for linkages between trade, technology, and wages. They also serve to illustrate why real world departures from the $2 \mathrm{x} 2$ theoretical world may muddle these same linkages in the actual data examined in the econometric literature.

We start with the standard 2x2 model. The theoretical structure is fleshed-out with 1995 data on production, trade, and intermediate and final demand for the United States. ${ }^{13}$ To keep within the rules spelled out by the $2 x 2$ model, we divide the full United States economy into a skilled- and unskilled-intensive sector. The skilled-intensive sector is the numeraire sector. We also assume that skilled and unskilled labour are the only factors of production. Production technology for value added (i.e. the full production function for a final goods-only model) is a CES technology. From the basic 2x2 Heckscher-O hlin structure, we systematically introduce modifications involving the assumptions of product homogeneity and inter-sectoral linkages. The resulting set of $2 x 2$ structures is spelled out below:

(1) A standard 2x2 model, with homogeneous final goods, CES production technologies, and Cobb-D ouglas preferences.

(2) A modification to the $2 \times 2$ model to include inter-sectoral linkages (Cobb-D ouglas based) in production, but keeping the assumption of homogeneous goods

(3) A further modification to (2), introducing Armington-type product differentiation.

(4) A further modification to (3), introducing Ethier/ Krugman type product

\footnotetext{
${ }^{13}$ These data are taken from the Global Trade Analysis Project (GTAP) dataset, which is a set of national social accounting matrices benchmarked to 1995. The definition of skilled and unskilled labor is based on occupational classifications. The models employed here, which are spreadsheet and GEMPACK based, are available upon
} 
differentiation, with monopolistic competition, in the skilled-intensive sector. ${ }^{14}$

Theoretically, we can summarize the relationship between real wages and prices in all these flavors of the $2 \times 2$ model as follows.

$$
w_{\text {real }}=G_{L}\left(P, P^{*}\right) / e\left(P, P^{*}\right)=w\left(P, P^{*}\right) / e\left(P, P^{*}\right)
$$

In equation (4), $\mathrm{w}_{\text {eel }}$ denotes the real wage rate relative to the price of utility $\left.\mathrm{eP}, \mathrm{P}^{*}\right)$. The GDP function is $G$, while from the envelope theorem, the first derivative with respect to $L, G_{L}$, is the nominal wage rate. It follows that, given price changes, the proportional change in real wages will be the following:

$$
\hat{w}_{\text {real }}=\left[\varepsilon_{w, P} \hat{P}-\varepsilon_{e, P} \hat{P}\right]+\left[\varepsilon_{w, P^{*}} \hat{P}^{*}-\varepsilon_{e, P^{*}} \hat{P}^{*}\right]
$$

In equation (5), the terms $\varepsilon_{\mathrm{ij}}$ are price elasticities for wand ewith respect to $\mathrm{P}$ and $\mathrm{P}^{*}$. In the Heckscher-O hlin model, the second set of terms in square brackets vanishes, while within the first term we know that $\left|\varepsilon_{w, p}\right|>1$. As we introduce differentiated products, the Pelements of the total price vector correspond to different elements of the total goods vector than do the $\mathrm{P}^{*}$ elements. The implications are two-fold, and are contained in the second term in brackets. In terms of goods prices, magnification may or may not hold, depending on the nature of intermediate flows. This depends on the magnitude and sign of the first arguments in both sets of square brackets. Even if magnification holds in terms of goods prices, it may not hold in terms of the price of utility. Basically, the combination of inter-sectoral linkages and differentiated products means that the magnified link between goods prices and welfare (i.e. income measured in units of utility as opposed to income measured in terms of goods prices) can break down.

\section{--Tables 1-3 about here--}

\footnotetext{
request.

${ }^{14}$ Under the Armington assumption, goods are differentiated by country of origin. Under monopolistic competition, this involves instead firm level product differentiation. See Hertel et al (1997) and Francois and Roland-Holst (1997).
} 
Tables 1 and 2 present numeric calculations that illustrate these relationships. The basic experiment in both tables involves a terms-of-trade shock that forces the price of the unskilledintensive good down by 1 percent. The reported elasticities hence correspond to the various combinations of the elements of equation (5) above. The elasticities in Table 1 relate to the term $\varepsilon_{w, p}+\varepsilon_{w, P^{*}}$. In the pure Heckscher-O hlin case, this is a single elasticity with respect to the price of the unskilled-intensive good. Reflecting magnification, it is greater than unity in absolute value. When we introduce intermediate linkages, the elasticity still reflects a single price change, and as discussed in section I, the magnification effect is itself magnified. In the last 2 columns, we have introduced differentiated products. Here, the term $\varepsilon_{w, P^{*}} \hat{P}^{*}$ is also relevant, as the 1 percent drop in $\mathrm{P}$ (i.e. $\hat{P}=-1$ ) is forced by a drop in $\mathrm{P}^{*}$. What these elasticities then tell us is that the sensitivity of internal prices (and hence wages) to changes in external prices is weakened when products are no longer homogeneous. In fact, in the example, magnification effectively breaks down. The elasticities in Table 2 relate to real income effects for the same cases as in Table 1, and hence reflect the full value of equation (5), given a terms-of-trade shock such that $\hat{P}=-1$. The first two columns reflect the standard result that, in a 2x2 model with homogeneous goods, there is an absolute winner and loser following a final goods price shock. What is interesting is that, once goods are differentiated (either by firms or by country of origin), we can lose the absolute winner rule. Under both heterogeneous goods specifications, we actually have both factors winning absolutely from the terms-of-trade improvement. This is most pronounced with firm-level product differentiation.

Table 3 presents results for a sector- and factor-biased technical change like that illustrated in Figure 3. Here, we have boosted the productivity of skilled labour in the numeraire sector in both differentiated product models. The result is a rise in real wages for skilled labour and a widening of the skilled-unskilled wage gap. This basic pattern holds under both scenarios. As reported at the bottom of the table, we also observe a divergent shift in factor intensities.

\section{NUMBERS WITH THEORY: ECONOMETRIC EVIDENCE}

Perhaps unsurprisingly, very little of the large body of empirical work on the relationship between international trade and wages has focussed on the Stolper-Samuelson theorem, or the general equilibrium framework directly. There is however, a small and very recent body of research that does just this. Specifically, three strategies have been adopted that "treat trade theory seriously". The first derives the a linear estimating equation directly from the standard Jones (1965) 
decomposition we discussed above; the second exploits the structure of national product functions; and the third adopts a less structural approach based on the vector-autoregression method. In this section we focus on this latter set of recent literature. It offers a set of results broadly consistent with the biased technical change story outlined in this paper.

Baldwin and Cain (1997), Leamer (1996), and Feenstra and Hanson (1997) all use an m factor x ngood decomposition of the relationship between proportional changes in unit costs and proportional changes in factor-prices based on the theoretical work of Jones (1965). ${ }^{15}$ Baldwin and Cain conclude that, except for the least skilled category in their sample (workers who did not finish high school), "increased imports of manufactured product intensively using less educated labour, by itself cannot explain the observed increase in wage inequality in the 1980s and 1990s among all groups of workers with more education compared with less education." (Baldwin and Cain, pg. 42). On the other hand, they conclude that "biased technical progress that is saving of the use of less educated labour and is more rapid in some manufacturing sectors intensive in the use of highly educated labour could have been the main force operating to decrease the relative wages of the 1-11 education group and to widen the gap between the 12 and 13+ education groups in manufacturing" (pg. 43).

Leamer (1996) and Feenstra and Hanson (1997) adopt a similar strategy to that of Baldwin and Cain, extending the basic framework to explicitly incorporate technological change. Leamer's strategy is to use data on technological change and an explicit assumption about the pass-through of a fixed proportion of that change to lower prices. Leamer concludes (pg. 30), like Baldwin and Cain, that technological change dominated price changes in the 1980s but that the reverse was true for the 1970s. Extending their research programme of incorporating the effects of outsourcing, Feenstra and Hanson decompose their measure of technological change into components due to high-technology equipment and outsourcing. ${ }^{16}$ Under an assumption of exogenous commodity prices and exogenous sector-specific wage differentials, Feenstra and Hanson find that outsourcing plays a large (though not precisely estimated) role in generating wage inequality. However, under pass-through assumptions like those in Leamer, technological change (computers) dominates other effects.

\footnotetext{
${ }^{15}$ We have already presented the result and its logic at equation (3). The original development of the empirical application of this decomposition can be found in Baldwin and Hilton (1984), who used this framework to predict trade flows between pairs of countries.

${ }^{16}$ See Feenstra and Hanson (1996 a and b) for development of their analysis and preliminary empirical results.
} 
An alternative general equilibrium approach exploits the well-known derivative properties of GNP functions to evaluate Stolper-Samuelson effects. ${ }^{17}$ In a very interesting recent paper, Harrigan and Balaban (1997) estimate a translog GNP function for the US for 1963-1991, for M $=\{$ High School Dropouts, High School Graduates, College Graduates, Capital $\}$ and $N=\{$ Nontraded Skill-Intensive, non-traded Unskilled-Intensive, Traded Skill-Intensive, Traded UnskilledIntensive ${ }^{18}$ As with the Jones-Baldwin approach, the GNP function approach allows Harrigan and Balaban to explicitly incorporate the effects of price changes (Stolper-Samuelson effects), endowment changes, and technology changes in a single econometric framework. This paper provides suggestive evidence that all three of these effects played a role in generating the increased inequality that emerged in the 1980s. ${ }^{19}$

A third, less structural, approach has been adopted in recent work by Francois, Navia, and Nelson (1998). Arguing that the Stolper-Samuelson theorem refers to a long-run relationship, the authors argue that, while the cross-section research might well not find any relationship between relative commodity prices and relative factor prices, the presence of cointegration between the series over time would provide evidence that such a relationship does hold. Using data for the US from 1967-1987, the authors construct price indexes for skilled-labour intensive and unskilledlabour intensive industries, and wage series for skilled and unskilled labour. Finding both series to be I(1), the authors test for cointegration, finding not only that the series are cointegrated, but that the sign of the relationship supports the Stolper-Samuelson theorem (i.e. that higher relative price of the skill-intensive good is associated with a higher relative wage of skilled labour). In addition,

${ }^{17}$ A useful fact, that has been exploited by Leamer (1993, section 6), is that, if the GNP function is twice differentiable, the Stolper-Samuelson derivatives are equal to the relevant Rybczynski derivatives. This fact, which follows from Young's theorem, is usually called Samuelson's reciprocity conditions.

${ }^{18}$ Burgess (1976) and Kohli (1991) pursue the same agenda with lower dimensional (i.e. 2 x2) models, but are not specifically interested in wage inequality. Burgess, does, however, present evidence that the US tariff protects labour. Kohli provides an excellent discussion of all aspects of this type of research. A recent paper by Harrigan (1997) is closely related. This paper also estimates a flexible functional form GNP function, but uses the information to evaluate the relative effects of factor endowments (the Rybczynski derivatives) and technological difference in explaining trade flows.

${ }^{19}$ In contrast to the conclusions of Baldwin and Cain, the effect of technological change was found to be considerably smaller in magnitude than the Stolper-Samuelson and endowment effects. However, the Harrigan/ Balaban framework assumes Hicks neutral technological change, where Baldwin and Cain argue that only biased change is consistent with the pattern of observed factor-price changes. 
the authors find bidirectional $\mathrm{G}$ ranger causality between these two variables. Finally, the variance decomposition shows that the relative price variable explains between 40 and 60 percent of the variance of the relative wage variable. ${ }^{20}$

\section{SUMMARY}

We have argued that the neoclassical, general equilibrium model is an extremely useful framework for discussing and evaluating the impact of international trade on the returns to labour market participation. Even in its simplest form (i.e. the 2x2 factor-endowment model), this model alerts us to the income distribution effects of international trade. While we find considerable support for the presence of Stolper-Samuelson effects, the framework is sufficiently flexible that it permits a wide range of conclusions as to the magnitude of these effects. This strikes us as good news. In an environment characterized by large changes in international trading conditions, it would be truly shocking if Stolper-Samuelson effects were not part of any empirical story about changing income distribution. At the same time, however, we must also recognize that there have also been dramatic changes in technology, government spending, labour market participation rates, and labour market institutions. It would be equally shocking if those factors did not matter as well. O ne of the signal virtues of simple general equilibrium modeling is that we are able to talk coherently about the ways, plausible and otherwise, that these phenomena might interact. Because of the complex ways in which these phenomena interact, it is almost surely impossible to convincingly isolate one or another effect as the single or primary mechanism. This unfortunate fact, however, should not lead us to turn away from the very real virtues of simple general equilibrium models for thinking about the world. There are certainly large differences of opinion with respect to empirical priors, detailed modeling strategy, and results between the main protagonists in this field (Edward Leamer, Paul Krugman, Robert Lawrence, James Harrigan, et al). However, thanks to their common use of wellspecified general equilibrium models in the HOS family, we are clear on the sources of their disagreement. Furthermore, surely as a result of their use of a common framework, this particular branch of the literature on the relationship between trade and wages is characterized by increasing theoretical clarity and empirical progress. From a social scientific point of view, one could hardly ask for more.

\footnotetext{
${ }^{20}$ It should be noted that the Francois, Navia, Nelson paper examines only the relationship between the dometicrelative commodity-price and the relative factor-price ratios, so it does not tell us about the relationship between tradeand wages.
} 


\section{References}

Baldwin, R. (1995). "The effects of trade and foreign direct investment on employment and relative wages". OECD Economic Studies \#23, pp. 7-54.

Baldwin, R. and Cain,G. (1997). "Shifts in US relative and absolute wages: the role of trade, technology and factor endowments". NBER WorkingPape, \#5934.

Baldwin, R. and Hilton,R.S. (1984). "A technique for indicating comparative costs and predicting changes in trade ratios". Reviewof Ecomomis and Statistics vol.66-no.1, pp. 105-110.

Bhagwati, J. (1959). "Protection, real wages, and real incomes". EconamicJaumal; vol.69-no.276, pp. 733-748.

Bhagwati, J. (1991). "Free traders and free immigrationists: strangers or friends". Russell Sage Foundation Working Paper \#20.

Burgess, D. (1976). "Tariffs and income distribution: some empirical evidence for the United States". Jaumal of Pditical Econamy, vol.84-no.1, pp. 17-45.

Chang, W. (1979). "Some theorems of trade and general equilibrium with many goods and factors". Economtrica, vol.47-no.3, pp. 709-726.

D eardorff, A. (1994). "Overview of the Stolper-Samuelson theorem". in A. D eardorff and R. Stern, eds. TheStdper-Samudson TheeremA GddenJubilee Ann Arbor: University of Michigan Press, pp. 734.

D eardorff, A. and Stern, R. (1994). TheStdper-Samudson Theorem A Gdden Jubilee Ann Arbor: University of Michigan Press.

D iewert, W.E. and Woodland,A. (1977). "Frank Knight's theorem in linear programming". Economitrica; vol. 45 no. 2, pp. 375-398.

Ethier, W.J. (1981). "Higher Dimensional Issues in Trade Theory". Chapter 3 in Jones, R. and Kenen, P. (eds) Handbodk of Intemational Econamics-Vd. I. Amsterdam: Elsevier, pp. 131-84.

Ethier,W.J., (1982). "National and international returns to scale in the modern theory of international trade." AmericanEconomicReviewvol 72-no.3, pp. 950-959.

Feenstra, R. and Hanson,G. (1997). "Productivity measurement and the impact of trade and technology on wages: estimates for the US, 1972-1990". NBER WorkingPaper, \#6052.

Findlay, R. and Grubert, H. (1959). "Factor-Intensities, Technological Progress and the Terms of Trade. OxfardEconomicPapas Vol. 11 no. ?, pp.111-121.

Francois, J.F. (1996) "Trade, Labour Force G rowth, and Wages," EconomicJaumal, Vol. 106-no.439, pp. 1586-1609. 
Francois, J.F., Navia, R., and Nelson, D . (1998). "Taking the Stolper-Samuelson Theorem Seriously: The Long-run Relationship". Ms: Murphy Institute.

Francois, J.F. and Roland-Holst, D.W. (1997). "Scale economies and imperfect competition." in J.F. Francois and K.A. Reinert, eds., Applied mothoods for tradepdigy analysis a handbodk, Cambridge University Press: New York.

Gaston, N. and Nelson, D. (1997). "Globalisation and Wages in OECD Economies: Linking Theory with Evidence". In Francois, J., Roland-Holst, D. and van der Mensbrugghe, D (forthcoming). Gldbalisation andEmployment Pattems Pdioy, Theryand Evidence London: CE PR.

Harrigan, J. (1997). "Technology, factor supplies, and international specialization: estimating the neoclassical model”. American EconamicReiew vol. .87 no.4, pp. 475-494.

Harrigan, J.and Balaban,R. (1997). "U.S. Wages in G eneral Equilibrium: Estimating the Effects of Trade, Technology, and Factor Supplies, 1963-1991”. ms.: Federal Reserve Bank of New York.

Hertel, T.W., Ianchivichina, E. and McD onald, B. (1997). "Multi-region general equilibrium modeling." in J.F. Francois and K.A. Reinert, eds., Appliøet mthoods for tradepdigyanalysis a handbodk, Cambridge University Press: New York.

Jones, R. (1965). "The structure of simple general equilibrium models". Jaumal of Pditical Econamy; vol..73 no. 6, pp. 557-572.

Jones, R. and Schinekman, J. (1977). "The relevance of the two-sector production model in trade theory". Jaumal of Pditical Econamy, vol.85 no.5, pp. 909-935.

Kohli, U. (1991). Tehndogy, Duality, andForeignTrade Ann Arbor: University of Michigan Press.

Krueger, A. (1997). "Labor Market Shifts and the Price Puzzle Revisited". NBER WorkingPaper, \#5924.

Krugman, P. and Lawrence, R. (1994). "Trade, Jobs and Wages”. ScietificAmeican April, pp. 44-49.

Lawrence, R. and Slaughter, M. (1993). "International Trade and American Wages in the 1980s: Giant Sucking Sound or Small Hiccup?”. Brookings Papess on EcomamicAdivity, Microeconomics, pp. 161-226.

Leamer, E. (1993). "Wage effects of a U.S.-Mexican free trade agreement." in TheU.S.-MexicoFræ TradeAgeement, Peter M. Garber, editor, MIT Press, pp.57-125.

Leamer, E. (1996). "In search of Stolper-Samuelson effects on US wages". NBER WorkingPaper \#5427.

Mantel, R. (1977). "Implications of microeconomic theory for community excess demand functions". in M. Intrilligator, ed. Fronties of QuantitativeEconomis, V.IIIA. Amsterdam: NorthHolland, pp. 111-126. 
Metzler, L. (1949). "Tariffs, the terms of trade, and the distribution of national income". Jamal of Pditical Economy, vol.57-no.1, pp. 1-29.

Puga, Diego and Venables, Anthony J. "Trading Arrangements and Industrial D evelopment," Policy Research Working Paper No. 1787, World Bank, June 1997.

Shafer, W. and Sonnenschein,H. (1982). "Market demand and excess demand functions". in K. Arrow and M. Intriligator, eds. Handbook of Mathematical Economis, V.II. Amsterdam: NorthHolland, pp. 671-693.

Shiells, C. and Thierfelder, K. (19 97). "Trade and labor market behavior." in J.F. Francois and K.A. Reinert, eds., Appliedmthods for tradepdigyanalysis a handbodk, Cambridge University Press: New York.

Sonnenschein, H. (1973). "D o Walras' Identity and Continuity Characterize the Class of Excess Demand Functions". Jarmal of EconmicThery, vol.6-no.4, pp. 345-354.

Stolper, W.and Samuelson. P. (1941). "Protection and real wages ." Reiewof EconomicStudę vol..9no.1, pp.58-73.

Wood, A. (1995). "How trade hurt unskilled workers." Jamal of EconomicPespeetives vol 9, pp. 5780. 
Fig. 1

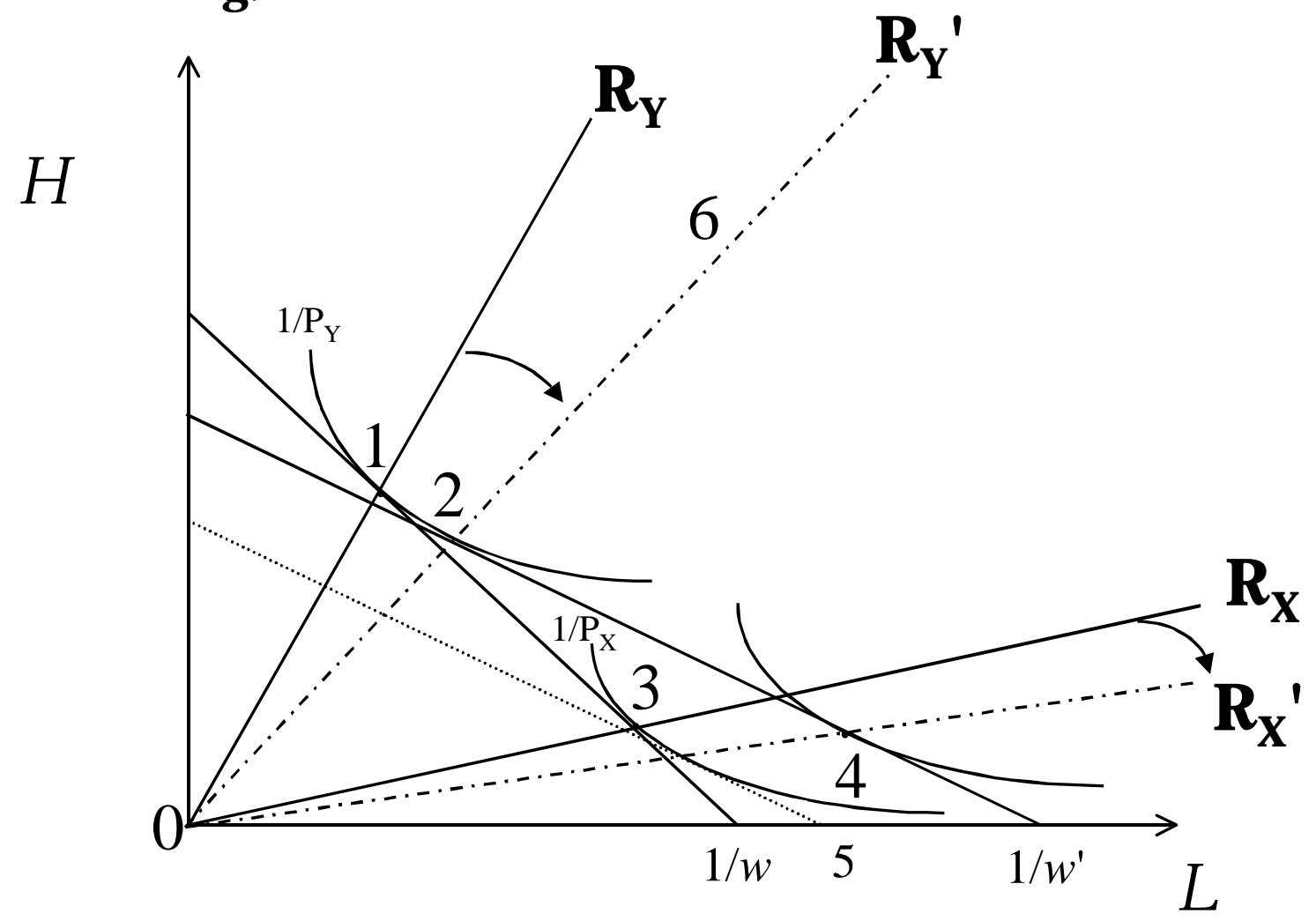

Goods prices, factor intensities, and factor incomes in the standard $2 \times 2$ model 


\section{Fig. 2}

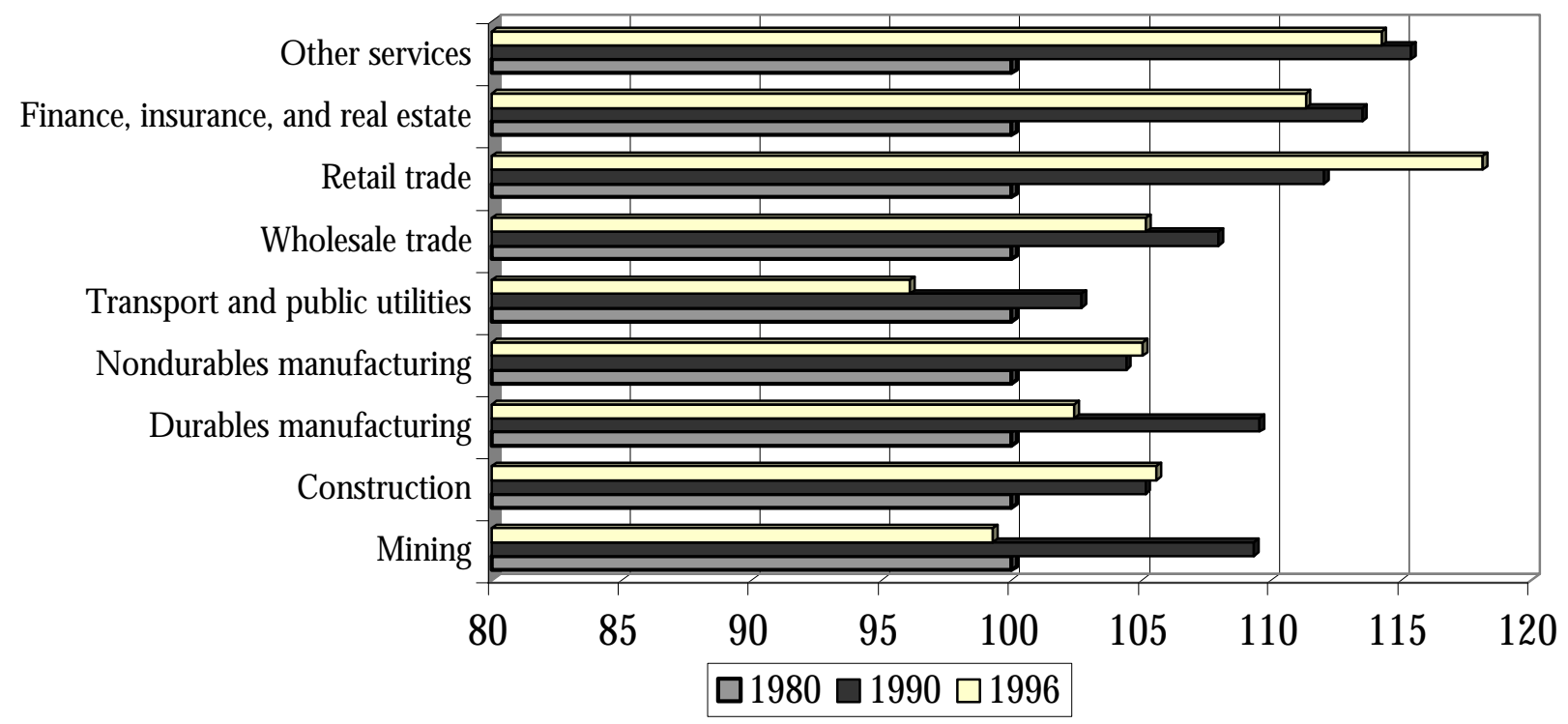

Skilled-labor share of sectoral U.S. employment, 1980=100 
Fig. 3

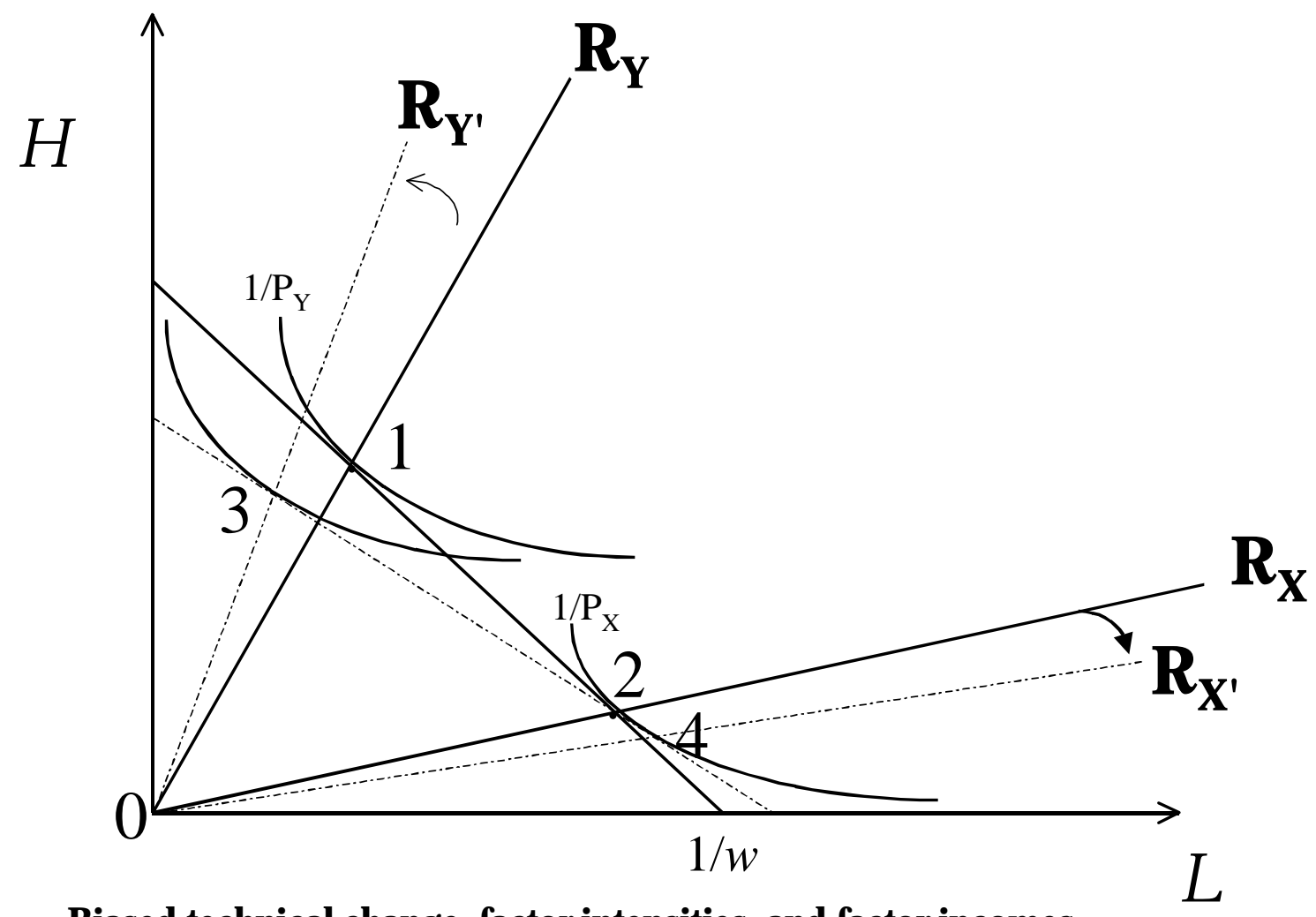

Biased technical change, factor intensities, and factor incomes 
Table 1-- Stopler-Samuelson elasticities in the $2 \times 2$ model

Estimates for the United States

\begin{tabular}{|c|c|c|c|c|}
\hline \multirow{2}{*}{ coles } & \multicolumn{2}{|c|}{ homogeneous goods } & \multicolumn{2}{|c|}{ heterogeneous goods } \\
\hline & final goods only & intermediates & Armington & monop. competition \\
\hline \multicolumn{5}{|l|}{ fador incomerdativeto thenumeraire } \\
\hline unskilled labor & -1.79 & & -0. & -0.53 \\
\hline skilled labor & 1.81 & & 0. & 1.04 \\
\hline relative skilled/ unskilled wage & 3.60 & & 1. & 1.57 \\
\hline
\end{tabular}

note: all estimates involve a trade-induced 1\% drop in the price of the unskilled-intensive good.

The numeraire is the final skill-intensive good price.

Table 2 -- Real income-price elasticities in the $2 \times 2$ model

Estimates for the United States

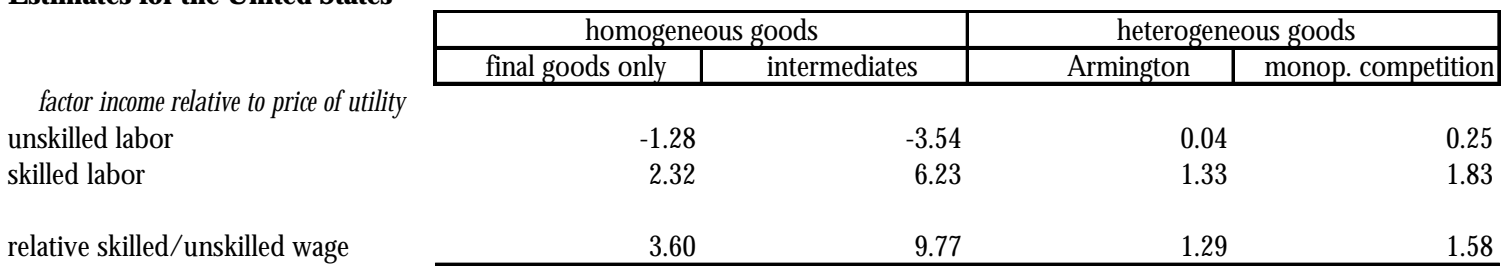

note: all estimates involve a trade-induced $1 \%$ drop in the price of the unskilled-intensive good.

The numeraire is the price of utility (based on a Cobb-D ouglas upper-tier utility function)

Table 3 -- Biased factor productivity elasticities in a 2x2 model

Estimates for the United States

\begin{tabular}{|c|c|c|c|}
\hline \multicolumn{2}{|c|}{ income relative to numeraire price } & \multicolumn{2}{c|}{ income relative to price of utility } \\
\hline Armington & monop. competition & Armington & monop. competition \\
\hline
\end{tabular}

biased productivity shok

unskilled labor

$0.25 \quad 0.31$

0.15

0.18

skilled labor

0.39

0.45

0.28

0.32

relative skilled/ unskilled wage

0.13

0.14

0.13

0.14

1/ Biased productivity shock involves productivity of skilled labor, which is boosted by $1 \%$ in the skill-intensive sector. note: ratio of skilled to unskilled labor, under the two model structures, changes as follows:

Armington: unskilled sector: -.18 , skilled sector: +.08

Monopolistic competition: unskilled sector: -.18, skilled sector +.07 